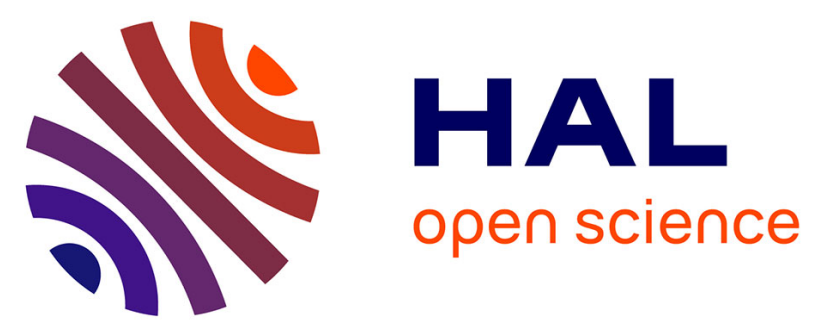

\title{
Glycoform Separation and Characterization of Cetuximab Variants by Middle-up Off-Line Capillary Zone Electrophoresis-UV/Electrospray Ionization-MS
}

Michael Biacchi, Rabah Gahoual, Nassur Said, Alain Beck, Emmanuelle Leize-Wagner, Yannis Francois

\section{To cite this version:}

Michael Biacchi, Rabah Gahoual, Nassur Said, Alain Beck, Emmanuelle Leize-Wagner, et al.. Glycoform Separation and Characterization of Cetuximab Variants by Middle-up Off-Line Capillary Zone Electrophoresis-UV/Electrospray Ionization-MS. Analytical Chemistry, 2015, 87 (12), pp.6240-6250. 10.1021/acs.analchem.5b00928 . hal-01981309

\section{HAL Id: hal-01981309 https://hal.science/hal-01981309}

Submitted on 14 Jan 2019

HAL is a multi-disciplinary open access archive for the deposit and dissemination of scientific research documents, whether they are published or not. The documents may come from teaching and research institutions in France or abroad, or from public or private research centers.
L'archive ouverte pluridisciplinaire HAL, est destinée au dépôt et à la diffusion de documents scientifiques de niveau recherche, publiés ou non, émanant des établissements d'enseignement et de recherche français ou étrangers, des laboratoires publics ou privés. 


\title{
Glycoform Separation and Characterization of Cetuximab Var- iants by Middle-up Off-line CZE-UV/ESI-MS
}

\author{
Michael Biacchi ${ }^{1}$, Rabah Gahoual ${ }^{1}$, Nassur Said ${ }^{1}$, Alain Beck ${ }^{2}$, Emmanuelle Leize-Wagner $^{1}$, Yannis- \\ Nicolas François ${ }^{1}$
}

\footnotetext{
${ }^{1}$ Laboratoire de Spectrométrie de Masse des Interactions et des Systèmes (LSMIS), UDS-CNRS UMR 7140; Université de Strasbourg; Strasbourg, France.

${ }^{2}$ Centre d'immunologie Pierre Fabre; Saint-Julien-en-Genevois, France.
}

\begin{abstract}
Monoclonal antibodies (mAbs) are highly complex glycoproteins that present a wide range of microheterogeneities that requires multiple analytical methods for full structure assessment and quality control. Capillary zone electrophoresis-Mass spectrometry couplings (CZE-MS), especially by Electrospray (ESI), appear really attractive methods for the characterization of biological samples. However, due to the presence of non- or medium volatile salts in the background electrolyte (BGE), online CZE-ESI-MS coupling is difficult to implement for mAbs isoforms separation. Here we report an original strategy to perform off-line CZE-ESI-MS using CZEUV/fraction collection technology to performed CZE separation, followed by ESI-MS infusion of the different fractions using CESI interface as nanoESI infusion platform. As the aim is to conserve electrophoretic resolution and complete compatibility with ESI-MS without sample treatment, Hydroxypropylcellulose (HPC) coated capillary was used to prevent analyte adsorption and assymetric CZE conditions involving different BGE at both ends of capillary have been developed. The efficiency of our strategy was validated with the separation of cetuximab charge variant by middle-up approach. Molecular weights were measured for six charge variants detected in the CZE separation of cetuximab subunits. The three first peaks correspond to Fc/2 variants with electrophoretic resolution up to 2.10 and the last three peaks correspond to $F\left(a b^{\prime}\right)_{2}$ variants with average electrophoretic resolution of 1.05. Two Fc/2 C-terminal lysine variants were identified and separated. Moreover separation of Fc/2 fragments allowed the glycoprofiling of the variants with the characterization of 7 different glycoforms. Regarding $\mathrm{F}\left(a b^{\prime}\right)_{2}$ domain, 8 glycoforms were detected and separated in three different peaks following the presence of $\mathrm{N}$ glycolyl neuraminic acid residues in some glycan structure. This work highlights the potential of CZE technology to perform separation of mAbs especially when they carry sialic acid carbohydrates.
\end{abstract}




\section{INTRODUCTION}

Since 1986 and the approbation of muromonab-CD3 by the US Food and Drug Administration (FDA), monoclonal antibodies (mAbs) have taken a major market share in the pharmaceutical industry and their development is constantly increasing ${ }^{1,2}$. MAbs are highly complex glycoproteins potentially displaying many naturally-occurring molecular micro-heterogeneities ${ }^{3,4}$. Patents protecting the first generation blockbuster mAbs will expire in the next 5 years, giving the opportunity to many companies to produce "biogeneric versions". These copies are referred as biosimilars. Biosimilarity assessment includes extensive physicochemical characterization likewise pharmacokinetic (PK) and pharmacodynamics (PD) study, performed in a comprehensive manner. Analytical high similarity is the most robust scientific basis for comparing independently sourced biologics ${ }^{5}$. As different structural heterogeneities emerged from comparison of a biosimilar candidate with the reference molecule, more complementary studies should be performed in order to demonstrate the absence of toxicological and negative clinical outcome ${ }^{6}$. As a consequence, there is a continuous need for improvement of analytical methods to enable fast and accurate characterization. Mass spectrometry (MS) generally coupled with separation methods such as high-performance liquid chromatography (HPLC), plays a key role in the characterization of therapeutic $\mathrm{AAbs}^{7}$. Many levels of characterization are performed following different strategies as intact molecular weight (MW) measurement, topdown, middle-up and bottom-up approaches ${ }^{7-9}$. Concerning glycosylation variants which is known as an important class of modification that can significantly impact the immunogenic properties of $\mathrm{mAbs}^{10}$, intact MW, middle-up on domain level, as well as bottom-up techniques were also performed ${ }^{11-14}$. However, at this point, no separation of mAbs glycoforms was obtained by HPLC-MS with intact MW or a middle-up approach ${ }^{15-17}$. As an alternative to HPLC, capillary zone electrophoresis (CZE) has been demonstrated to be an useful and powerful separation method for the characterization of intact proteins ${ }^{18,19}$. CZE and related methods using optical detections were fully established at all stages of mAbs discovery. However, due to the presence of high concentration of non-volatile salts in the background electrolyte (BGE) necessary for mAbs variants separation, development of CZE coupled with MS detection have been limited. Recently we published several research papers on bottom-up characterization of $\mathrm{mAbs}$ and biosimilars highlighting the potential of CZE-ESI-MS to obtain full primary structure and microvariant characterization as well as biosimilarity assessment ${ }^{12-14}$. However, in bottom-up approach, BGE is totally compatible with ESI-MS, whereas for an intact MW or a middle-up approach, BGE involves high concentration in nonvolatile salt or detergent which preclude the use of ESI-MS ${ }^{20-22}$. To our knowledge, some groups defined CZE-UV conditions for the separation of intact mAbs involving always high levels of $\varepsilon$-amino-caproic acid (EACA) and the addition of triethylenetetramine (TETA) or Tween $20^{23-27}$. Despite very interesting results in the separation of charge variants, BGEs are totally incompatible with ESI-MS ${ }^{28}$. In 2014, we developed the first analysis of intact 
mAb charge variant by CZE using a matrix-assisted laser desorption/ionization-MS (MALDI) detection ${ }^{29-31}$. Unfortunately, limitation of MALDI-MS resolution does not allow to measure the exact mass of the charge variants. More recently, Redman et al published an important paper on the first characterization of intact mAb variants using microfluidic CZE-ESI devices ${ }^{28}$.

In this work, we developed a strategy to perform off-line CZE-UV/ESI-MS with the use of CZE-UV/fraction collection technology to performed CZE separation, followed by ESI-MS infusion of the different fractions using CESI interface as nanoESI platform. Hydroxypropylcellulose (HPC) coating was used to minimize analyte adsorption on the capillary wall and reduce electroosmotic mobility (EOF). As one of the aim is to be compatible with ESI-MS, assymetric CZE conditions bringing into play different BGE at the ends of capillary have been developed. Inlet BGE composed of EACA $200 \mathrm{mM}$ and ammonium acetate $25 \mathrm{mM}, \mathrm{pH}$ 5.70, allowed to conserve performance of CZE separation while outlet BGE composed only of ammonium acetate $25 \mathrm{mM}$ allowed to be compatible with ESI-MS. Based on the work of Gahoual et al we used CESI interface as nanoESI infusion platform allowed us to generated stable spray at $100 \mathrm{~nL} / \mathrm{min}$ with sample consumption of $2 \mu \mathrm{L}$ per fraction avoiding dilution effect ${ }^{32}$. The mAb selected was cetuximab which is human/murine chimeric IgG-1 directed against the epidermal growth factor receptor (EGFR) overexpressed in advanced-stage EGFR positive colorectal cancer ${ }^{33}$. Cetuximab was approved in the US and EU in 2004 and 2005, respectively and will be off-patent soon. Cetuximab contains two sites of glycosylation on the HC: one is located in the $\mathrm{Fc} / 2$ domain $\left(A s n^{299}\right)$ and the second is located in the $\mathrm{F}\left(\mathrm{ab} \mathrm{b}^{\prime}\right)_{2}$ domain on $\mathrm{Asn}{ }^{887}$ (Figure 1). It is an ideal sample for the evaluation of our strategy by middle-up approach. Indeed, cetuximab subunits characterization allowed to locate and to identify glycoforms. The performance of our strategy is demonstrated by the characterization of C-terminal lysine variants and the first separation of glycoforms of cetuximab subunits using CZE-UV off-line hyphenated to ESI-MS after fraction collection. 


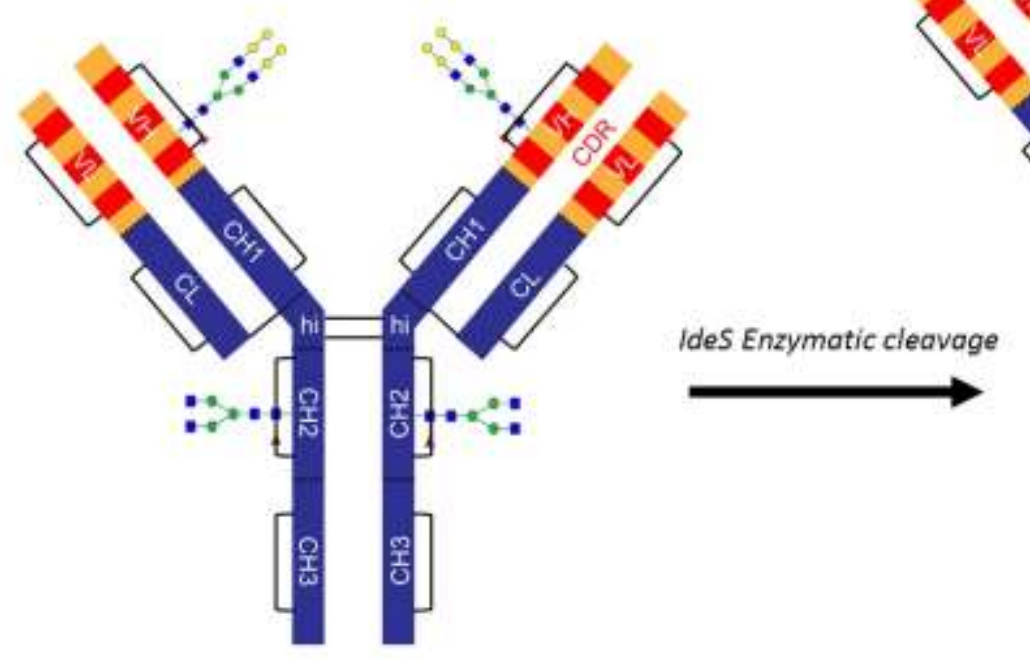

Cetuximab (ChlgG 1)

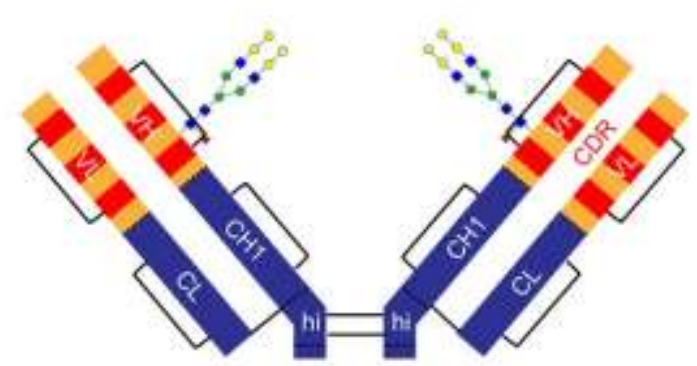

$\mathrm{F}\left(\mathrm{ab}^{\prime}\right)_{2}$

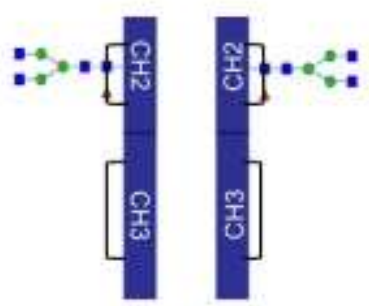

$\mathrm{F}_{\mathrm{c} / 2}$

Figure 1. Schematic representation IdeS enzymatic cleavage of cetuximab. cetuximab is a chimeric IgG: human amino acids are highlighted in blue (constant domains), murine amino acids in orange (frameworks) and in red (the complementary determining region)

\section{- EXPERIMENTALS SECTION}

Materials. Methanol (HPLC gradient grade) and acetic acid (100\%) were obtained from VWR (Radnor, PA, USA). Ammonium acetate(>98\%), sodium hydroxide, $\varepsilon$-Amino-caproic acid (>98\%), hydroyxypropylcellulose Mw 100000 (HPC) and formic acid (>98\%) were purchased from Sigma-Aldrich (Saint Louis, MO, USA). Water used to prepare buffers and sample solutions was obtained using an ELGA purelab UHQ PS water purification system (Bucks, UK). IdeS (Immunoglobulin-degrading enzyme of Streptococcus pyogenes) also named FabRICATOR was purchased from Genovis (Lund, Sweden). Cetuximab (Erbitux ${ }^{\circledR}$, Merck KGaA, Darmstadt, Germany) is a sterile, preservativefree solution for intravenous infusion containing $5 \mathrm{mg} / \mathrm{mL}$ of cetuximab. The other ingredients are sodium chloride, glycine, polysorbate 80 , citric acid monohydrate, sodium hydroxide and water for injections.

Middle-up sample preparation. Cetuximab was cleaved in the hinge region using limited proteolysis by IdeS (FabriCATOR, Genovis) to obtain two Fc/2 fragments (calculated pl 7.74) and one $F\left(a b^{\prime}\right)_{2}$ fragment (calculated pl 7.78) (Figure 1). Sample was diluted using $147.25 \mu \mathrm{L}$ of $50 \mathrm{mM}$ sodium phosphate, $150 \mathrm{mM} \mathrm{NaCl}, \mathrm{pH} 6.60$, to a final concentration of $1 \mu \mathrm{g} / \mu \mathrm{L}$. A volume of $2.25 \mu \mathrm{L}$ of IdeS (67 units/ $\mu \mathrm{L}$ ) was added to the sample which was left at $37^{\circ} \mathrm{C}$ for $30 \mathrm{~min}$. After digestion completion, sample was desalted using Amicon centrifugal filters (cut off $=10,000$ $\mathrm{Da}$ ) in pure water at $10^{\circ} \mathrm{C}$ and $14,000 \mathrm{~g}$ for $20 \mathrm{~min}$. After desalted step, sample volume was reduced to around 10 
$\mu \mathrm{L}$. Sample was finally diluted to an assumed final concentration of $5 \mu \mathrm{g} / \mu \mathrm{L}$ in a total volume of $30 \mu \mathrm{L}$ of pure water.

Capillary electrophoresis. The CZE experiments were carried out on a P/ACE MDQ ${ }^{\mathrm{TM}}$ CE system from Sciex Separation (Brea, CA) equipped with a UV detection, a temperature controlled autosampler and a power supply able to deliver up to $30 \mathrm{kV}$. A 32 Karat $^{\mathrm{TM}} 8.0$ (Sciex Separation, Brea, CA) was used for instrument control, data acquisition and data handling. Polymicro bare fused-silica capillaries of $75 \mu \mathrm{m}$ i.d., 375 o.d. (75.5 cm effective length, 82 $\mathrm{cm}$ total length) were obtained from Photonlines (St-Germain-en-Laye, France). New capillaries were conditioned by successive flushes with $1.00 \mathrm{M}$ and $0.10 \mathrm{M} \mathrm{NaOH}$ and then with water under a pressure of 30 psi for $10 \mathrm{~min}$ each. The temperature in the capillary cartridge and autosampler were set at $25^{\circ} \mathrm{C}$. The acquisition rate was 10 points / s. Capillaries were rinsed with water and dried by air when not in use. UV absorbance fixed at $200 \mathrm{~nm}$. Voltage applied at $20 \mathrm{kV}$ with a ramp of 0.17 and injection sample condition was $0.5 \mathrm{psi}$ for $50 \mathrm{~s}$. Concerning modified capillaries, capillaries were coated in laboratory with hydroyxypropylcellulose Mw 100000 (HPC) following the protocol described by Shen et $a l^{34} .5 \%$ HPC in pure water $(w / v)$ was prepared to perform capillary coating. Durability of coating is around 20 runs without recoating step. For Cetuximab separation, inlet BGE $200 \mathrm{mM} \varepsilon$ Amino-caproic acid (EACA)-ammonium acetate $25 \mathrm{mM} \mathrm{pH} 5.70$ and outlet BGE ammonium acetate $25 \mathrm{mM} \mathrm{pH}$ 5.70 have been used as separation condition. Injection volumes have been calculated using CEToolbox application (Pansanel, GooglePlay).

CZE/Collection Fraction Interface. This interface is describe in a previous study ${ }^{31}$. Briefly, automated off-line coupling of CZE to MS was performed by using a homemade modified automatic spotting device Proteineer FC (Bruker Daltonics, Bremen, Germany) for the sheath flow-assisted spotting from the CZE capillary end onto a fraction collection target. The original set up of the UV cell in the P/ACE MDQ ${ }^{\mathrm{TM}}$ (Sciex Separation, Brea, CA) was modified in order to allow the simultaneous UV detection and fraction collection. Hystar 3.2 (Bruker Daltonics, Bremen, Germany) was used for Proteineer FC control.

CESI as nanoESI infusion platform. The infusion experiments were carried out with a PA 800 plus capillary electrophoresis (CE) system from Sciex Separation (Brea, CA) equipped with a temperature controlled autosampler and a power supply able to deliver up to $30 \mathrm{kV}$. Prototype fused-silica capillaries (total length $95 \mathrm{~cm} ; 30 \mu \mathrm{m}$ i.d.) whose outlet end (about $3 \mathrm{~cm}$ ) was etched with hydrofluoric acid were used for all related CESI experiments and initially provided by Sciex Separation (Brea, CA, USA). It is certainly noteworthy to precise here that the inner lumen of these capillaries is not tapered and presents an i.d. of $30 \mu \mathrm{m}$ throughout its entire length. New capillaries were initially conditioned by flushing them for $10 \mathrm{~min}$ with $\mathrm{MeOH}, 10 \mathrm{~min}$ with $0.10 \mathrm{M}$ sodium hydroxide, $10 \mathrm{~min}$ with $0.10 \mathrm{M}$ hydrochloric acid and finally with water for 20 min each flushing step being conducted at 75 psi (5.17 bar). 
MALDI-TOF-MS. The matrix was prepared by dissolving 2,5-dihydroxybenzoic acid (DHB) (2g/L) in 0.1\% trifluoroacetic acid/acetonitrile (TFA/ACN) (30/70)(v/v). Fraction collection was realized using Ground Steel MALDI target (Bruker Daltonics, Bremen, Germany). Mass spectra of the CZE fractions were recorded using an Autoflex II MALDITOF (Bruker Daltonics, Bremen, Germany), operating in reflector mode and with FlexControl software. Positively charged ions were detected and sums of 1500 single-shot spectra were acquired automatically from each sample by using the AutoXecute software. Data processing was performed with FlexAnalysis 3.0 provided by the mass spectrometer manufacturer. All spectra were calibrated according an external calibration using Protein calibration standard I (Bruker Daltonics, Bremen, Germany) for intact protein separation.

ESI-TOF-MS. For sheathless CZE-ESI-MS experiments the CE system was coupled to a maxis 4G (Bruker Daltonics, Bremen, Germany). MS transfer parameters were optimized using the actual sample directly infused via the CE system using a pressure of $5 \mathrm{psi}$ (340 mbar). MS parameters were optimized so that high $\mathrm{m} / \mathrm{z}$ ions could be properly transferred to the TOF analyzer while avoiding fragmentation. In the case of the maxis $4 \mathrm{G}$, ion funnels were set at values of $300 \mathrm{Vpp}$ and $400 \mathrm{Vpp}$. The electrospray voltage (capillary voltage) was typically ranging from -1.2 to -1.8 $\mathrm{kV}$. Dry gas was set at $1.5 \mathrm{~L} / \mathrm{min}$ and source temperature at $180^{\circ} \mathrm{C}$. Data processing was performed with DataAnalysis 4.0. Deconvolution of the mass spectra was performed based on maximum entropy analysis using ESI Compass 1.3 Maximum Entropy Deconvolution Option in DataAnalysis 4.0. All spectra were calibrated by external calibration using Pepmix (Bruker Daltonics, Bremen, Germany) and CsI from Sigma-Aldrich (Saint-Louis, MO, USA).

\section{- RESULTS AND DISCUSSION}

Optimization of CZE separation conditions.

As the aim is to develop a procedure for the middle-up characterization of cetuximab using the potential of CZE separation method and suitable for ESI-MS direct infusion, we have optimized BGEs as mixtures of components that facilitate isoforms separation and allow the use of ESI ionization process. First we based our research on the study developed by the group of Pr. Somsen on the glycoform profiling of interferon- $\beta$ - 1 a and erythorprotietin ${ }^{19}$. However, using condition based on HPC coated capillary and $50 \mathrm{mM}$ acid BGE, no separation of cetuximab isoforms had been obtained. To our knowledge, some groups defined CZE-UV conditions for the separation of intact mAbs involving always high levels of EACA and the addition of TETA or Tween 2023-27. EACA is a zwitterion which can be used to create high ionic strength and low conductivity buffers that minimize the electroosmotic flow (EOF) and improve electrophoretic mobility differences. TETA and Tween 20 behave as a modifier in BGE for dynamic coating to reduce prevent analyte adsorption in the capillary wall ${ }^{35-37}$. Despite very interesting results in the separation of charge variants due to the presence of these modifiers, the major issue of these BGE conditions is the incompatibility with ESI-MS detection. The first step of our optimization consisted to eliminate Tween 20 and TETA of the 
BGE. Indeed, following the results described by Gassner et al, we minimize analyte adsorption only by the use of a HPC coating ${ }^{25}$. This allows to remove the use of additional detergent or oligoamine, and it additionally presents the advantage of being a static coating that avoid potential polymer release for ESI-MS infusion. In a previous work, we demonstrated the high repeatability and the good robustness obtained with HPC-coated capillary for the separation of intact $m A b s$ (RSD $<0.5 \%$, migration time) ${ }^{31}$. The second step of our BGE screening concerned the use of high level of EACA. He et al demonstrated the influence of $\mathrm{pH}$ and EACA concentration on the mAb separation $^{23}$. Concerning EACA concentration, they demonstrated that increasing EACA concentration may improve separation efficiency and electrophoretic resolution. However, due to zwitterionic properties, EACA based BGE involve significant interference with the sample in the ionization process of ESI-MS. Despite this, the presence of EACA in the BGE remains essential to maintain the separation efficiency particularly due to the low conductivity. Based on the results of Ruesch's team ${ }^{23}$ and some difficulties of matrix/sample crystallization for MALDI-MS experiment observed in previous study, we decided to reduce the EACA concentration from $400 \mathrm{mM}$ to $200 \mathrm{mM}$ and to add ammonium acetate at a pH of 5.70. Ammonium acetate is usually employed with ESI-MS mainly for volatility properties of the ammonium ion and good compatibility with the process of ionization. To perform separation we used our homemade CZE-UV/fraction collection described in a previous work ${ }^{31}$. BGEs are placed in the inlet and outlet vials of the CE apparatus. Due to the modification of CE cartridge, outlet BGE has been used as sheath liquid with a flow rate of $0.5 \mu \mathrm{L} / \mathrm{min}$. Fraction collection was directly deposit on a target plate. Each peak is collected on the basis of its apparent mobility described by the equation:

$$
\mu_{a p p}=\frac{\mathrm{Ll}}{\mathrm{t}_{m} \mathrm{~V}}
$$

with $\mu_{\text {app }}$ the apparent mobility which is the sum of effective mobility and residual EOF, L and I the total capillary length and length to detection window, respectively, $\mathrm{V}$ the applied voltage and $\mathrm{t}_{\mathrm{m}}$ the migration time. Deposition time $t_{d}$ is then calculated by the equation:

$$
t_{d}=\frac{L^{2}}{\mu_{a p p} V}
$$

The results presented Figure 2 show the CZE-UV separation of cetuximab IdeS fragments (Figure 1) with different BGEs at pH 5.70 composed by the mixture of EACA $200 \mathrm{mM}$ and various concentration of ammonium acetate from $5 \mathrm{mM}$ to $50 \mathrm{mM}$. Electropherograms presented Figure 2 show a drastic decrease of electrophoretic resolution with lowest concentration of ammonium acetate until complete loss of separation with $5 \mathrm{mM}$ ammonium acetate (electropherogram A). These results confirm the trend in loss of electrophoretic resolution with the decrease of the ionic strength. Electropherogram D corresponding to BGE composed by EACA 200mM ammonium acetate $50 \mathrm{mM} \mathrm{pH} 5.70$, show the best separation with electrophoretic resolution up to 1.63 for peak 1-3 corresponding to $\mathrm{Fc} / 2$ variants and an average electrophoretic resolution of 1.02 for peak 4-6 corresponding to $F\left(a b^{\prime}\right)_{2}$ variants. 
However, outlet BGE which plays the role of sheath liquid is composed of $200 \mathrm{mM}$ EACA which can compromise the ESI-MS ionization process. Indeed, to verify the impact of the presence of EACA in the BGE, we perform MALDIMS mass spectra of the different fractions corresponding to the six major peaks. No signals were observed by MALDI-MS because of the lack of crystallization of the sample with the DHB matrix (Figure S-1 part A). Presence of EACA in the BGE gives white homogenous deposit totally different of the spangled classical one. MALDI-MS detection failure and the experimental ESI-MS infusion of fraction 3 without any MS signal (data not shown) allows us to conclude that direct ESI-MS infusion is completely impossible in these conditions.

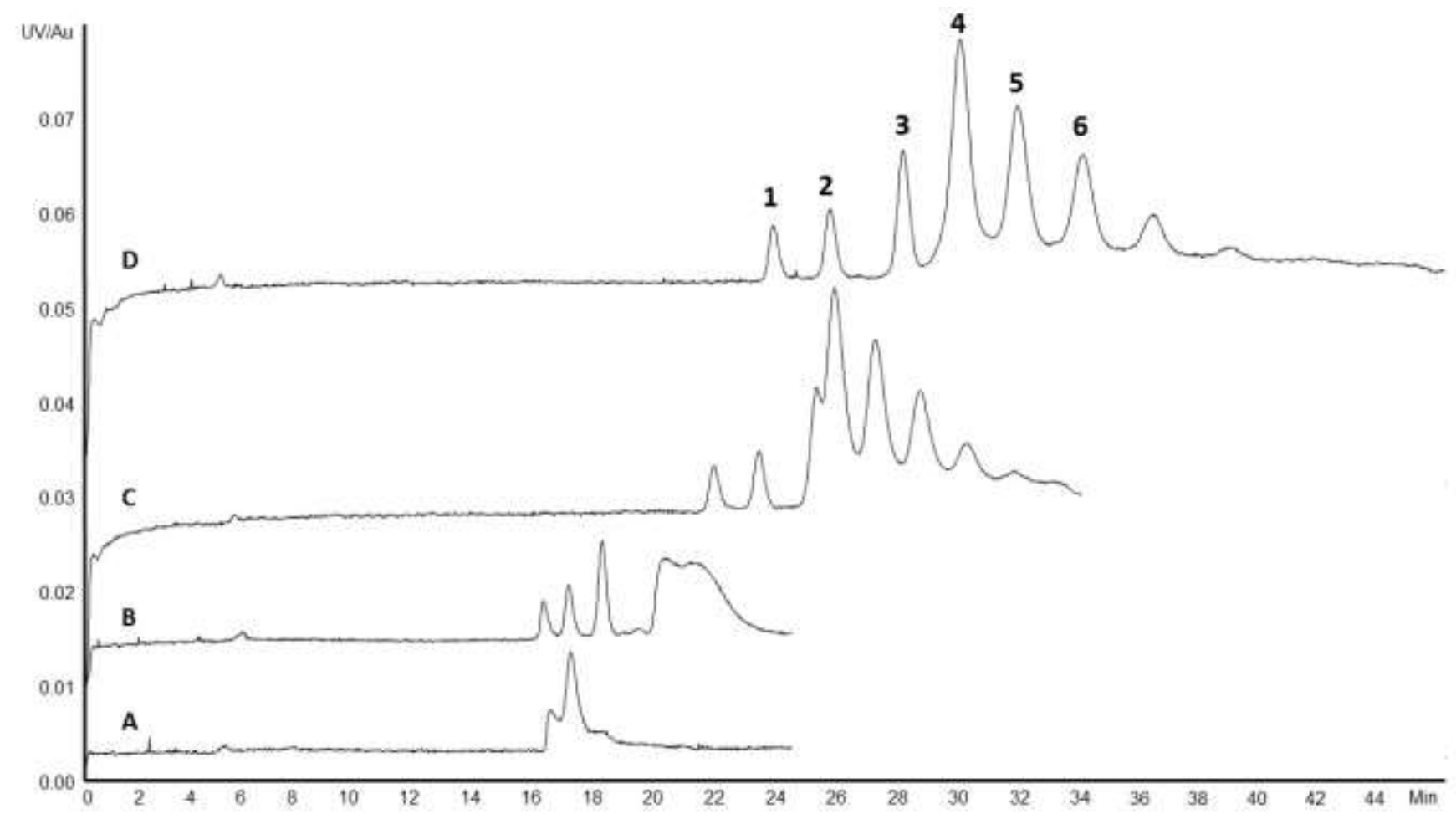

Figure 2. Impact of ammonium acetate concentration in BGE on electrophoretic resolution. BGE composed by a mixture of EACA 200 mM and acetate ammonium (A) $5 \mathrm{mM}$, (B) $10 \mathrm{mM}$, (C) $25 \mathrm{mM}$ and (D) $50 \mathrm{mM}$, at pH 5.70. Peak 1-3 correspond to Fc/2 variants and peak 4-6 correspond to $\mathrm{F}\left(\mathrm{ab}^{\prime}\right) 2$ variants. Experimental conditions: HPC-coated capillary, total/effective length $82 / 75.5 \mathrm{~cm} \times 75 \mu \mathrm{m}$ i.d.; voltage, 20 $\mathrm{kV}$; UV absorbance at $200 \mathrm{~nm}$; sample, IdeS digest of cetuximab $(5 \mu \mathrm{g} / \mu \mathrm{L})$; sample injection $0.5 \mathrm{psi} 50 \mathrm{~s}$.

Based on the CZE-ESI-MS sheath liquid interface described by the group of $\mathrm{Smith}^{38}$, and the fact that additional liquid is usually different of BGE composition, we decided to develop asymmetric conditions between the inlet BGE and the outlet BGE. As the aim of the study is to conserve the electrophoretic resolution of the separation, to allow ESI-MS detection and to avoid the Joule heating effect, inlet BGE has been chosen as EACA $200 \mathrm{mM}$ and ammonium acetate $25 \mathrm{mM} \mathrm{pH}$ 5.70. A different BGE, placed in the outlet vial, is composed only with ammonium acetate at $\mathrm{pH} 5.70$. 
To optimize the separation, different concentration of ammonium acetate from 12.5 to $100 \mathrm{mM}$ have been tested as outlet BGE. Results are presented in Figure 3. Electropherogram C and D show a loss of electrophoretic resolution between peak 3 and peak 4 corresponding to the last peak of $F c / 2$ variants and the first peak of $F\left(a b^{\prime}\right)_{2}$ variants. Electropherogram B corresponding to outlet BGE composed by ammonium acetate $25 \mathrm{mM} \mathrm{pH} \mathrm{5.70,} \mathrm{show}$ the best separation with electrophoretic resolution up to 2.10 for peak 1-3 corresponding to $\mathrm{Fc} / 2$ variants and an average electrophoretic resolution of 1.05 for peak 4-6 corresponding to $F\left(a b^{\prime}\right)_{2}$ variants. These results show no loss of electrophoretic resolution using electropherogram B conditions as compared to the Figure 2 experiments. This demonstrates that the presence of high concentration of EACA in the outlet BGE is not necessary to achieve the separation. As the aim was to verify the impact of the absence of EACA in the outlet BGE, we performed a MALDI-MS detection of the different fractions corresponding to the six major peaks. First of all, we observed a good crystallization of sample with DHB matrix (Figure S-1 part B) which confirms no contamination of EACA during deposit process. Figure 4 emphasizes mass spectrum of each peak. Moreover, the CZE-MALDI-MS (Fig. 4b) confirms the good agreement between the UV detection and the deposition time in terms of $F c / 2$ and $F\left(a b^{\prime}\right)_{2}$ separation. This also confirms the absence of carryover effect and diffusion phenomenon. Unfortunately, limitation of MALDI-MS resolution for molecules up to $20 \mathrm{kDa}$ does not allow to measure the exact mass of the charge variants and then to characterize thoroughly these glycoproteins. Thus, to reach higher MS resolution at comparable separation efficiency, we switched to ESI-MS detection using CESI as nanoESI infusion platform. This strategy of collection fraction followed by nanoESI infusion opens the way for a deeper characterization of Fc/2 and $F\left(a b^{\prime}\right)_{2}$ domains without sample treatment and with minimum sample volume $(2 \mu \mathrm{L})$.

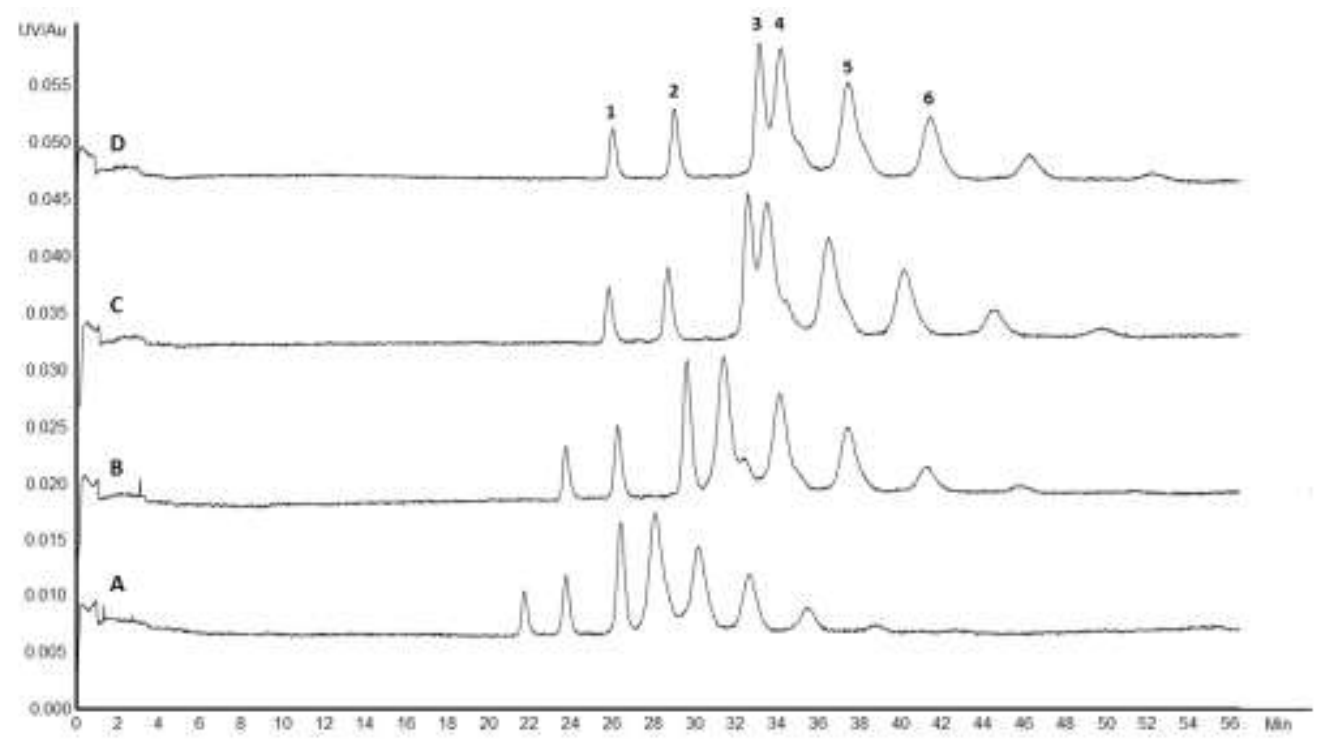

Figure 3. Impact of ammonium acetate concentration in outlet BGE on electrophoretic resolution. Inlet BGE composed by a mixture of EACA $200 \mathrm{mM}$ and acetate ammonium $25 \mathrm{mM} \mathrm{pH} 5.70$ and outlet BGE by ammonium acetate (A) $12.5 \mathrm{mM}$, (B) $25 \mathrm{mM}$, (C) $50 \mathrm{mM}$ and (D) $100 \mathrm{mM}$, at pH 5.70. Peak 1-3 correspond to Fc/2 variants and peak 4-6 correspond to F(ab')2 variants. Experimental conditions: HPCcoated capillary, total/effective length $82 / 75.5 \mathrm{~cm}$ x $75 \mu \mathrm{m}$ i.d.; voltage, $20 \mathrm{kV}$; UV absorbance at $200 \mathrm{~nm}$; sample injection 0.5 psi $50 \mathrm{~s}$. 

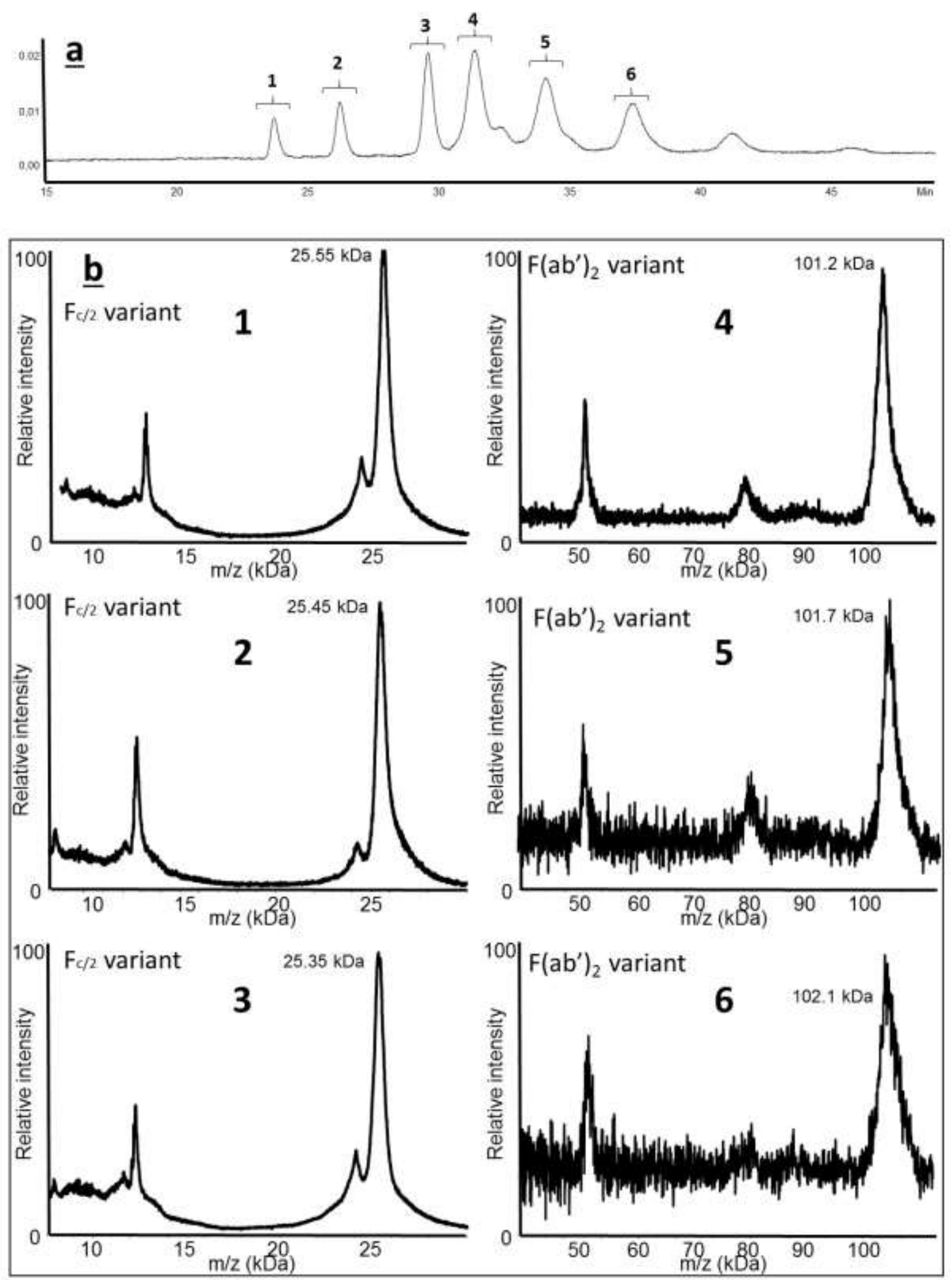

Figure 4. CZE-UV off-line coupled to MALDI-MS via fractionation for a middle-up characterization of Cetuximab charge variants. (a) CZE-UV electropherogram. (b) Analysis of CZE-UV fractions by MALDI-MS. Mass spectra of the six major peaks. CE Experimental conditions: Inlet BGE: EACA $200 \mathrm{mM}$ acetate ammonium $25 \mathrm{mM} \mathrm{pH} 5.70$ and outlet BGE: ammonium acetate $25 \mathrm{mM}$ pH 5.70; other conditions: See Figure 2, MS Experimental conditions: See Experimental section; sample, IdeS digest of cetuximab (5 $\mathrm{g} / \mathrm{\mu L})$; sample injection 0.5 psi $50 \mathrm{~s}$. 
Middle-up characterization of cetuximab

Cetuximab is a chimeric mouse-human IgG1 known to bear $2 \mathrm{~N}$-glycosylation sites on each heavy chain (HC) ${ }^{11}$. Moreover, cetuximab has a large number of microheterogeneities such as PTMs including methionine oxidation, asparagine deamidation or isomerization of aspartic acid. Furthermore, this mAb also has one C-terminal lysine truncation. These features make cetuximab an ideal sample for the evaluation of a middle-up approach using CEMS coupling. In order to simplify the location of $\mathrm{N}$-glycosylation, IdeS enzymatic reaction (Figure 1 ) cleaves cetuximab in the middle of $\mathrm{HC}$ to obtain two types of fragments each carrying one N-glycosylation site. Direct ESI-MS infusion of IdeS fragments of cetuximab proved equal signal abundances for C-terminal lysine variants which involves two distinct profiles for the Fc/2 domains, and a complex glycoprofiling for the $\mathrm{F}\left(\mathrm{ab} \mathrm{b}^{\prime}\right)_{2}$ domain (Figure S-2). With this knowledge, we can expect to observe few peaks corresponding to Fc/2 fragments due to a loss of a +1 charge associated with C-terminal lysine truncation. In addition, we also expect few peaks for $F\left(a b^{\prime}\right)_{2}$ fragments because of the ability of CZE to resolve glycoforms with acidic glycans, due to a reduction in net charge by addition of negatively charged sialic acid compound. Preliminary MALDI-MS results presented in Figure 4 confirmed these predictions with peak 1-3 corresponding to Fc/2 fragments and at least peak 4-6 corresponding to $F\left(a b^{\prime}\right)_{2}$ fragments.

To enhance MS resolution, the same experiment was performed to collect fractions of each peaks and to analyze them by nanoESI-MS using CESI interface as infusion platform. After deposition, each fraction was collected and evaporated. No special treatment was made on collected fractions. Before infusion, dry samples were reconstituted in $2 \mu \mathrm{L}$ of $50 \% / 49 \% / 1 \%$, acetonitrile/water/formic acid $(\mathrm{v} / \mathrm{v} / \mathrm{v})$ in order to enhance sample ionization. Thus, each fraction was infused into the MS using a flow rate of $100 \mathrm{~nL} / \mathrm{min}$ in order to enhance sensitivity. The total volume of sample infused to perform one acquisition was about $600 \mathrm{~nL}$ which represents a 100 times reduction in terms of sample consumption as compared to standard ESI-MS. This point is critical as the volume of each fraction does not expect few $\mu \mathrm{L}$ to avoid dilution effect.

Deconvoluted charge variant mass spectrum of fractions from peak 1 to peak 3 generated multiple masses corresponding to the expected presence of neutral glycosylation variants of $\mathrm{Fc} / 2$ fragments (Figure 5). In addition, the comparison with the direct infusion experiment (Figure S-2) shown us that the two Fc/2 fragments corresponding to intact and with one lysine truncation are detected and separated. Deconvoluted mass spectra corresponding to peak 1 and peak 3 show a difference of 128 Da between mass peak 25359.1 Da corresponding to the most abundant Fc/2 glycoform (GOF) and mass peak 25231.1 Da corresponding to GOF for Fc/2-K. Thus, we obtained the complete separation of these two fragments (Figure 5-b 1 and 3). In agreement with Ayoub et al and with the comparison of direct infusion of cetuximab IdeS subunits (Figure S-2), only one possibility of C-terminal lysine loss 
was expected. Regarding, deconvoluted mass spectra of peak 2, it shows a nearly equal abundance mixture of $\mathrm{Fc} / 2$ and Fc/2-K variants. These peaks deconvolute to the same MWs founded to peak 1 and peak 3 and could be interpreted by an overlap during the deposit process. However, regarding the MS signal of raw data used to generate deconvoluted spectra of peak 1, peak 2 and peak 3, and considering a potential equivalent ionization efficiency of all Fc/2 variants, intensity of peak 2 is higher than that of peak 1 and less than that of peak 3 (Figure S3) following the CZE separation pattern. This observation should eliminates a potential carryover effect (peak broadening, excessive diffusion) which should show a concomitant decrease of peak 1 MS intensity and increase of peak 2 MS intensity. In addition, to exclude carryover effect, we performed infusion of fractions corresponding to peak 4 and to a period of 2 min before detection of peak 1. No ESI-MS spectra have been detected corresponding to Fc/2 fragment (data not shown). Cetuximab, as other mAbs, is known to have a large number of microheterogeneities commonly found in proteins which are reflected by differences in mass, charge or conformation and then differences in effective mobilities. Moreover, it is plausible that several cumulative modifications could lead to a variation of conformation without mass shifts. Although further work is required to identify these modifications.

An important class of modification that can significantly impact the immunogenic properties of cetuximab in terms of PK and PD is glycosylation ${ }^{10}$. Cetuximab contains two sites of glycosylation on the HC: one is located in the Fc/2 domain $\left(A s n^{299}\right)$ and the second is located in the $F\left(a b^{\prime}\right)_{2}$ domain on $A s n^{88} 7$. Cetuximab has been widely described in terms of glycan characterization ${ }^{4,39}$. In 2013, Janin-Bussat et al used a middle-up approach similar to the one described here but using HPLC-MS method, and identified 17 different glycoforms distributed on the two glycosylation sites ${ }^{40}$. In 2013, team of Dr. Beck characterized 24 different glycosylation using the combination of intact, middle-up, middle-down and bottom-up ESI and MALDI-MS techniques ${ }^{11}$. More recently Gahoual et al characterized 15 glycopeptides using a bottom-up approach by CESI-MS/MS ${ }^{13}$. In our work, we could identify a total of 15 glycans divided among 7 for the $\mathrm{Fc} / 2 \mathrm{~N}$-glycosylation and 8 for the $\mathrm{F}\left(\mathrm{ab}{ }^{\prime}\right)_{2} \mathrm{~N}$-glycosylation (Table S-1 and Table S2). Regarding Fc/2 domain, branched glycan structures are primarily composed of fucose, $\mathrm{N}$-acetylglucosamine, and mannose but can differ in the number of terminal galactose, mannose or $\mathrm{N}$-acetylglucosamine residues. Glycan structure with the addition of galactose moieties involves a mass increase of 162 Da but does not induce a change in net charge $\mathrm{e}^{41,42}$. Gahoual and coworkers demonstrated that particular glycopeptides having a difference of one galactose could be baseline separated ${ }^{13}$ whereas Redman et al did not observed mobility shifts between intact mAb glycoforms due to the low impact of $162 \mathrm{Da}$ on the mass of intact mAb $(\approx 0.1 \%)^{28}$. Our work demonstrated that concerning glycoform with a difference of one galactose residue, middle-up approach does not allow to observe baseline separations. The mass of galactose moiety accounts for $\approx 0.6 \%$ of the $\mathrm{Fc} / 2$ domain and $\approx 0.2 \%$ of the $F\left(a b^{\prime}\right)_{2}$ domain. Following the conclusion of Redman et al, to induce effective mobility shift, the mass in- 
crease would have to be much greater or induce a significant change in conformation. However, CE has the potential to separate glycoforms bearing acidic residues, due to a reduction in net charge from the addition of negatively charged sialic acid ${ }^{41}$. In this point, cetuximab appears to be an ideal sample.

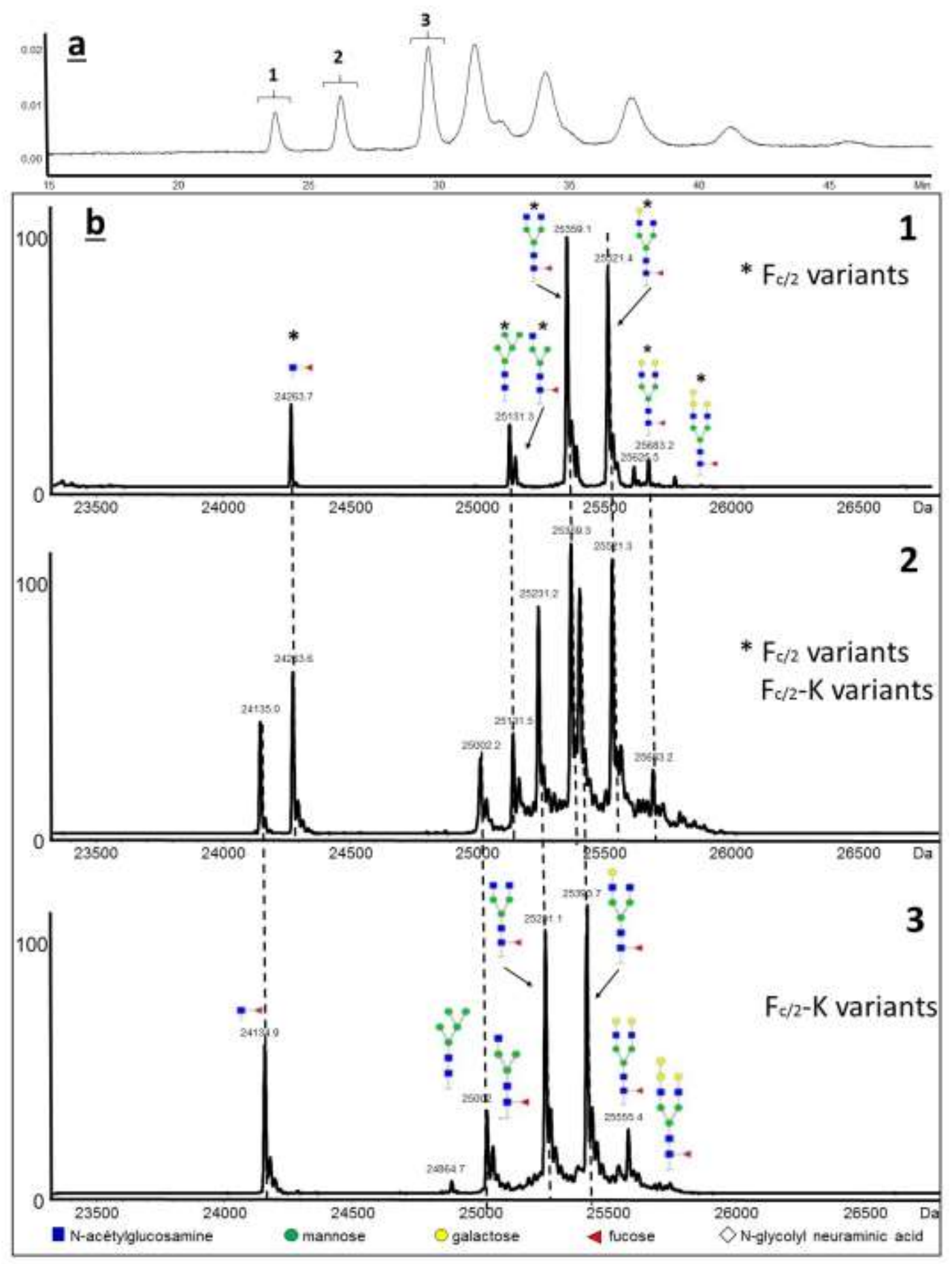

Figure 5. (a) Off line CZE-UV/ESI-MS separation of middle-up cetuximab charge variants. (b) Deconvoluted mass spectra for each Fc/2 variant. The MS peak were labeled with the correspondent glycoform. Experimental conditions: Inlet BGE: EACA $200 \mathrm{mM}$ ammonium acetate $25 \mathrm{mM} \mathrm{pH} 5.70$ and outlet BGE: ammonium acetate $25 \mathrm{mM} \mathrm{pH} \mathrm{5.70;} \mathrm{other} \mathrm{conditions:} \mathrm{See} \mathrm{Figure} \mathrm{2,} \mathrm{MS} \mathrm{Experimental} \mathrm{conditions:} \mathrm{See}$ Experimental section; sample, IdeS digest of cetuximab $(5 \mu \mathrm{g} / \mu \mathrm{L})$; sample injection 0.5 psi $50 \mathrm{~s}$. 


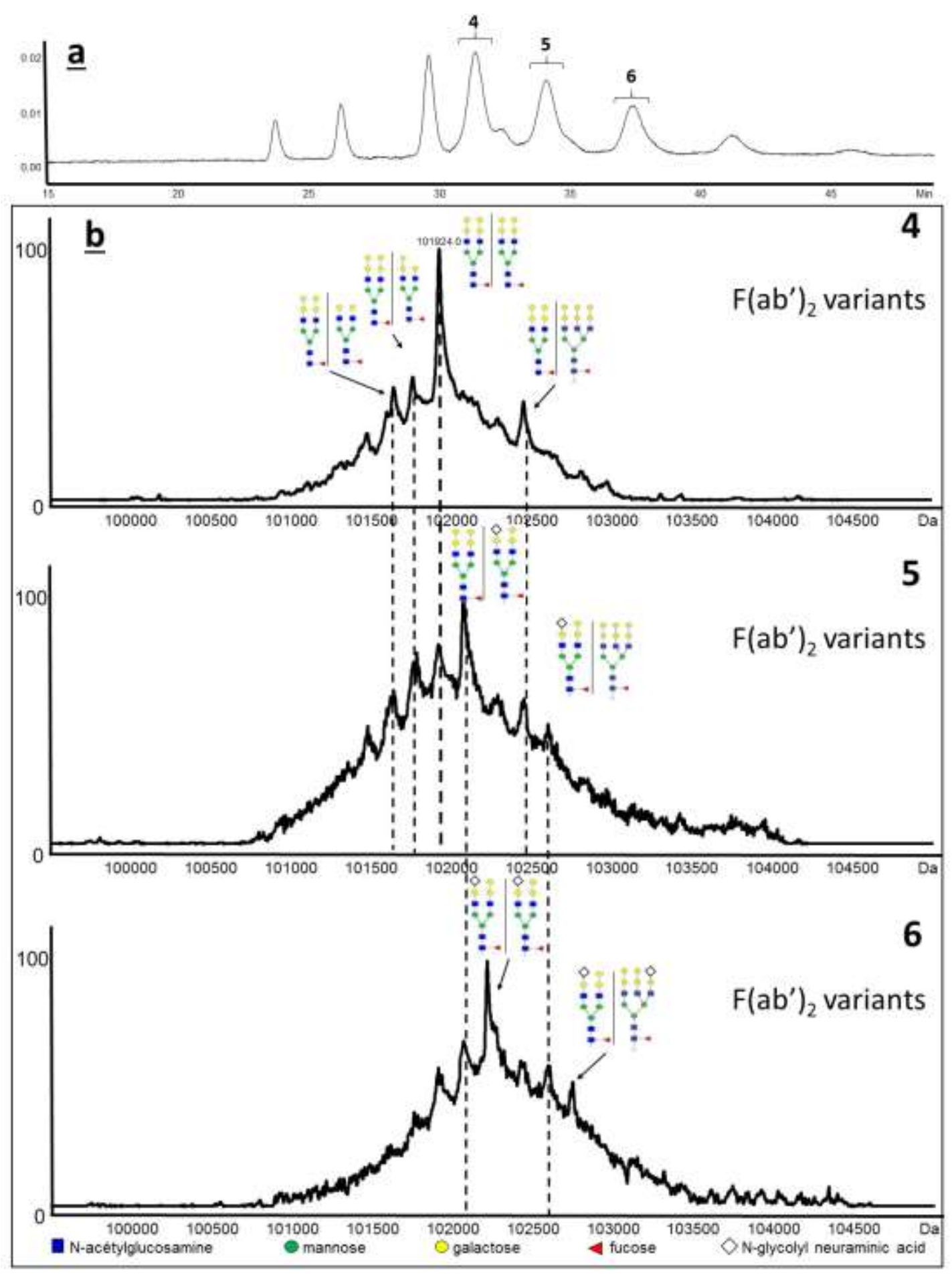

Figure 6. (a) Off line CZE-UV/ESI-MS separation of middle-up cetuximab charge variants. (b) Deconvoluted mass spectra for each $\mathrm{F}\left(\mathrm{ab} \mathrm{b}^{\prime}\right)_{2}$ variant. The MS peak were labeled with the correspondent glycoform. Experimental conditions: Inlet BGE: EACA $200 \mathrm{mM}$ ammonium acetate $25 \mathrm{mM} \mathrm{pH} 5.70$ and outlet BGE: ammonium acetate $25 \mathrm{mM}$ pH 5.70; other conditions: See Figure 2, MS Experimental conditions: See Experimental section; sample, IdeS digest of cetuximab $(5 \mu \mathrm{g} / \mu \mathrm{L})$; sample injection 0.5 psi $50 \mathrm{~s}$. 
Indeed, regarding $\mathrm{F}\left(\mathrm{ab}^{\prime}\right)_{2}$ domain, Ayoub et al identified glycosylations with $41 \%$ glycans bearing N-glycolyl neuraminic acid (NGNA) in their structures. NGNA glycoforms result from the SP2/0 murine expression system used to produce cetuximab ${ }^{43}$. When produced in $\mathrm{CHO}$ cells, biobetter version exhibit $\mathrm{N}$-acetylneuraminic acid (NANA) glycoforms ${ }^{9}$. Despite the high proportion of the NGNA glyclan, no separation of $F\left(a b^{\prime}\right)_{2}$ variants was obtained using HPLC-MS ${ }^{11}$. As shown in Figure 6, electrophoretic peaks from 4 - 6 correspond to different $F\left(a b^{\prime}\right)_{2}$ variants. Deconvolution of each charge variant mass spectrum generated multiple masses, corresponding for peak 4 to the expected presence of neutral glycosylation variants. Following the theory developed previously for the Fc/2 variants, neutral residues did not allow effective mobility shift of $F\left(a b^{\prime}\right)_{2}$ glycoforms due to the small impact of galactose mass residue in the $\mathrm{F}\left(\mathrm{ab}^{\prime}\right)_{2}$ mass. The mass ascribed to the most intense mass peak $101924 \mathrm{Da}$ (Figure 6b-4) correspond to the most abundant $F\left(a b^{\prime}\right)_{2}$ glycoform (G2FGal2/ G2FGal2). Four other less abundant F(ab') ${ }_{2}$ glycoforms are labeled each one bearing galactose residues (Figure 6b-4). Deconvoluted mass spectra presented in Figure $6 b-5$ correspond to the $F\left(a b^{\prime}\right)_{2}$ glycoforms contained in peak 5 . In this fraction the most abundant mass peak 102069 Da present a mass difference of 145 Da compared to GF2Gal2/ GF2Gal2 which corresponds to the presence of a NGNA residue instead of a galactose residue. This mass peak corresponds to the second most abundant F(ab') $)_{2}$ glycoform (GF2Gal2/ GF2GalNGNA). Another mass peak at 102592 Da has been labeled in the mass spectra. This corresponds to a less abundant $\mathrm{F}\left(\mathrm{ab}^{\prime}\right)_{2}$ glycoform also bearing one NGNA residue in the glycan structure. We note that common mass peaks are detected in fraction 4 and 5. Indeed, the electrophoretic resolution of 1.05 does not allow the complete separation however we observe an important decrease of intensity for the glycoforms detected in fraction 4. Finally, the infusion of fraction 6 corresponding to the sixth peak of the electrophoretic separation (Figure 6b-6), gives deconvoluted mass spectra corresponding to $F\left(a b^{\prime}\right)_{2}$ glycoforms with the combination of glycan structures each bearing one NGNA residue (GF2GaINGNA/GF2GaINGNA). Indeed, the most intense peak showing a deconvoluted mass of 102217 Da also presents a difference of 145 Da compared to GF2GaINGNA/GF2GaINGNA which correspond to the presence of a second NGNA residue instead of a galactose residue. Moreover, as in fraction 5, another mass peak at $102741 \mathrm{Da}$ has been detected and correspond to a less abundant in the $\mathrm{F}\left(\mathrm{ab} \mathrm{b}_{2}\right)_{2}$ glycoforms also each bearing one NGNA residue in the glycan structures. To our knowledge, these results represent the first separation of $F\left(a b^{\prime}\right)_{2}$ glycoforms using CZE-MS coupling. Knowing that these glycosylations have been shown to be responsible for immunogenic responses ${ }^{10}$, separation of these glycoforms can be very helpful for the characterization of cetuximab especially to highlight batch-to batch variations in the glycosylation profiles or for biosimilarity assessment. Furthermore, no similar results have been described using HPLCMS coupling. This highlights the potential of CZE separation to perform middle-up approach of mAbs especially when they carry capping sialic acid carbohydrates.

\section{- CONCLUSION}


To summarize, we have reported an original strategy bringing into play off-line CZE-UV/fraction collection method followed by nanoESI-MS infusion for the characterization of a therapeutic mAb. In order to realize mAb charge variants separation and to perform nano-ESI-MS detection, CZE conditions were optimized. First, to eliminate BGE additives, HPC coated capillary utilized to obtain residual EOF and to minimize analyte adsorption. Second, as the aim is to conserve electrophoretic resolution and complete compatibility with ESI-MS, assymetric CZE conditions involving different BGE at the ends of capillary have been described. Inlet BGE has been chosen as a mixture of EACA 200 mM/ammonium acetate 25 mM, pH 5.70 and outlet BGE composed of only ammonium acetate 25 mM, $\mathrm{pH}$ 5.70. MWs were measured for six charge variants detected in the CZE separation of cetuximab subunits through deconvolution of the mass spectra. The three first peaks correspond to $\mathrm{Fc} / 2$ variants and the last three peaks correspond to $\mathrm{F}\left(\mathrm{ab} \mathrm{b}_{2}\right)_{2}$ variants. Separation performance obtained with these conditions shown electrophoretic resolution up to 2.10 for $\mathrm{Fc} / 2$ variants and an average electrophoretic resolution of 1.05 for $F\left(a^{\prime}\right)_{2}$ variants. Regarding Fc/2 domain, two C-terminal lysine variants were identified and separated. Moreover the separation of Fc/2 fragments allowed the glycoprofiling of the variants with the characterization of 7 glycoforms each bearing neutral residues to the glycan structure. Regarding $\mathrm{F}\left(a b^{\prime}\right)_{2}$ domain, deconvolution of the mass spectra allowed the determination of 8 glycoforms detected and separated in different peaks. Glycoforms separation is due to the presence of NGNA residues in some glycan structure. Four glycosylations of $F\left(a b^{\prime}\right)_{2}$ variants were identified by characteristic 145 Da mass shift, moreover this identification was supported by the decrease of effective mobility due to a reduction in net charge from the addition of negatively charged sialic acid. To our knowledge, this work represent the first demonstration of middle-up approach of mAb using CZE-MS and in addition the first separation of $F\left(a b^{\prime}\right)_{2}$ glycoforms. This highlights the potential of CZE to perform separation of mAbs especially when they carry sialic acid groups. Moreover, the strategy of collection fraction followed by nanoESI infusion without sample treatment and in sample volume of $2 \mu \mathrm{L}$ open the way to different deeper characterization with for example a topdown approach using ESI-ETD-MS most likely unraveling additional information regarding the structure of the protein.

\section{Acknowledgments}

Authors would like to thank Sciex separations Inc. for lending a CESI prototype and Dr. M. Anselme from Sciex separations Inc. for his support. The authors would like also to express their gratitude to Dr. E. Wagner-Rousset, Dr. D. Ayoub, MC. Janin-Bussat and O. Colas (Centre d'Immunologie Pierre Fabre, St Julien en Genevois, France) for helpful discussions around antibody structural characterization

\section{Supporting Information Available}


Additional information about crystallization of matrix/sample in presence or not of EACA, direct ESI-MS infusion of cetuximab, MS raw data of fraction 1-6 and theoretical and measured masses of identified glycoforms as noted in the text. Information is available free of charge via the Internet at http://pubs.acs.org/.

\section{References}

(1) Beck, A.; Wurch, T.; Bailly, C.; Corvaia, N. Nat Rev Immunol 2010, 10, 345-352.

(2) Reichert, J. M. mAbs 2012, 4, 413-415.

(3) Arnold, J. N.; Wormald, M. R.; Sim, R. B.; Rudd, P. M.; Dwek, R. A. Annu Rev Immunol, 2007, 25, 21-50.

(4) Zhang, Z. Q.; Pan, H.; Chen, X. Y. Mass Spectrom Rev 2009, 28, 147-176.

(5) McCamish, M.; Woollett, G. Clin Pharmacol Ther 2013, 93, 315-317.

(6) Beck, A.; Diemer, H.; Ayoub, D.; Debaene, F.; Wagner-Rousset, E.; Carapito, C.; Van Dorsselaer, A.; SanglierCianferani, S. Trac-Trend Anal Chem 2013, 48, 81-95.

(7) Beck, A.; Sanglier-Cianferani, S.; Van Dorsselaer, A. Anal Chem 2012, 84, 4637-4646.

(8) Beck, A.; Wagner-Rousset, E.; Ayoub, D.; Van Dorsselaer, A.; Sanglier-Cianferani, S. Anal Chem 2013, 85, 715736.

(9) Beck, A.; Debaene, F.; Diemer, H.; Wagner-Rousset, E.; Colas, O.; Dorsselaer, A. V.; Cianférani, S. J Mass Spectrom 2015, 50, 285-297.

(10) Chung, C. H.; Mirakhur, B.; Chan, E.; Le, Q.; Berlin, J.; Morse, M.; Murphy, B. A.; Satinover, S. M.; Hosen, J.; Mauro, D.; Slebos, R. J.; Zhou, Q. W.; Gold, D.; Hatley, T.; Hicklin, D. J.; Platts-Mills, T. A. E. New Eng J Med 2008, 358, 1109-1117.

(11) Ayoub, D.; Jabs, W.; Resemann, A.; Evers, W.; Evans, C.; Main, L.; Baessmann, C.; Wagner-Rousset, E.; Suckau, D.; Beck, A. Mabs 2013, 5, 699-710.

(12) Gahoual, R.; Burr, A.; Busnel, J. M.; Kuhn, L.; Hammann, P.; Beck, A.; Franccois, Y. N.; Leize-Wagner, E. Mabs 2013, 5, 479-490.

(13) Gahoual, R.; Busnel, J.-M.; Beck, A.; François, Y.-N.; Leize-Wagner, E. Anal Chem 2014, 86, 9074-9081.

(14) Gahoual, R.; Biacchi, M.; Chicher, J.; Kuhn, L.; Hammann, P.; Beck, A.; Leize-Wagner, E.; Francois, Y. N. Mabs 2014, 6, 1464-1473.

(15) Talebi, M.; Nordborg, A.; Gaspar, A.; Lacher, N. A.; Wang, Q.; He, X. Z. P.; Haddad, P. R.; Hilder, E. F. J Chromatogr A 2013, 1317, 148-154.

(16) Mokaddem, M.; Gareil, P.; Varenne, A. Electrophoresis 2009, 30, 4040-4048.

(17) Alvarez, M.; Tremintin, G.; Wang, J.; Eng, M.; Kao, Y.-H.; Jeong, J.; Ling, V. T.; Borisov, O. V. Anal Biochem 2011, $419,17-25$.

(18) Haselberg, R.; Ratnayake, C. K.; de Jong, G. J.; Somsen, G. W. J Chromatogr A 2010, 1217, 7605-7611.

(19) Haselberg, R.; de Jong, G. J.; Somsen, G. W. Anal Chem 2013, 85, 2289-2296.

(20) Fekete, S.; Gassner, A. L.; Rudaz, S.; Schappler, J.; Guillarme, D. Trac-Trend Anal Chem 2013, 42, 74-83.

(21) Farnan, D.; Moreno, G. T. Anal Chem 2009, 81, 8846-8857.

(22) Rozhkova, A. J Chromatogr A 2009, 1216, 5989-5994.

(23) He, Y.; Lacher, N. A.; Hou, W.; Wang, Q.; Isele, C.; Starkey, J.; Ruesch, M. Anal Chem 2010, 82, 3222-3230.

(24) He, Y.; Isele, C.; Hou, W.; Ruesch, M. J Sep Sci 2011, 34, 548-555.

(25) Gassner, A. L.; Rudaz, S.; Schappler, J. Electrophoresis 2013, 34, 2718-2724.

(26) Shi, Y.; Li, Z.; Qiao, Y. B.; Lin, J. J Chromatogr B 2012, 906, 63-68.

(27) Espinosa-de la Garza, C. E.; Perdomo-Abundez, F. C.; Padilla-Calderon, J.; Uribe-Wiechers, J. M.; Perez, N. O.; Flores-Ortiz, L. F.; Medina-Rivero, E. Electrophoresis 2013, 34, 1133-1140.

(28) Redman, E. A.; Batz, N. G.; Mellors, J. S.; Ramsey, J. M. Anal Chem 2015, 87, 2264-2272.

(29) Amon, S.; Plematl, A.; Rizzi, A. Electrophoresis 2006, 27, 1209-1219.

(30) Silvertand, L. H. H.; Toraño, J. S.; de Jong, G. J.; van Bennekom, W. P. Electrophoresis 2009, 30, 1828-1835. 
(31) Biacchi, M.; Bhajun, R.; Saïd, N.; Beck, A.; François, Y. N.; Leize-Wagner, E. Electrophoresis 2014, 35, 29862995.

(32) Gahoual, R.; Busnel, J. M.; Wolff, P.; Francois, Y. N.; Leize-Wagner, E. Anal Bioanal Chem 2014, 406, 1029-1038.

(33) Dubois, M.; Fenaille, F.; Clement, G.; Lechmann, M.; Tabet, J.-C.; Ezan, E.; Becher, F. Anal Chem 2008, 80, 17371745.

(34) Shen, Y. F.; Smith, R. D. J. Microcolumn Sep. 2000, 12, 135-141.

(35) Legaz, M. E.; Pedrosa, M. M. J Chromatogr A 1996, 719, 159-170.

(36) Verzola, B.; Gelfi, C.; Righetti, P. G. J Chromatogr A 2000, 868, 85-99.

(37) Punzet, M.; Ferreira, F.; Briza, P.; van Ree, R.; Malissa Jr, H.; Stutz, H. J Chromatogr B 2006, 839, $19-29$.

(38) Smith, R. D.; Olivares, J. A.; Nguyen, N. T.; Udseth, H. R. Anal Chem 1988, 60, 436-441.

(39) Qian, J.; Liu, T.; Yang, L.; Daus, A.; Crowley, R.; Zhou, Q. W. Anal Biochem 2007, 364, 8-18.

(40) Janin-Bussat, M.-C.; Tonini, L.; Huillet, C.; Colas, O.; Klinguer-Hamour, C.; Corvaïa, N.; Beck, A. In Glycosylation Engineering of Biopharmaceuticals, Beck, A., Ed.; Humana Press, 2013, pp 93-113.

(41) Liu, H. C.; Gaza-Bulseco, G.; Faldu, D.; Chumsae, C.; Sun, J. J Pharm Sci 2008, 97, 2426-2447.

(42) Raju, T. S.; Scallon, B. J. Biochem Biophys Res Co 2006, 341, 797-803.

(43) Beck, A.; Wagner-Rousset, E.; Bussat, M. C.; Lokteff, M.; Klinguer-Hamour, C.; Haeuw, J. F.; Goetsch, L.; Wurch, T.; Van Dorsselaer, A.; Corvaia, N. Curr Pharm Biotechno 2008, 9, 482-501. 


\section{CAPTIONS}

Figure 1. Schematic representation IdeS enzymatic cleavage of cetuximab. cetuximab is a chimeric IgG: human amino acids are highlighted in blue (constant domains), murine amino acids in orange (frameworks) and in red (the complementary determining region)

Figure 2. Impact of ammonium acetate concentration in BGE on electrophoretic resolution. BGE composed by a mixture of EACA 200 mM and acetate ammonium (A) $5 \mathrm{mM}$, (B) $10 \mathrm{mM}$, (C) $25 \mathrm{mM}$ and (D) $50 \mathrm{mM}$, at pH 5.70. Peak 1-3 correspond to Fc/2 variants and peak 4-6 correspond to $\mathrm{F}\left(\mathrm{ab} \mathrm{b}^{\prime}\right) 2$ variants. Experimental conditions: HPC-coated capillary, total/effective length $82 / 75.5 \mathrm{~cm} \times 75 \mu \mathrm{m}$ i.d.; voltage, 20 kV; UV absorbance at $200 \mathrm{~nm}$; sample, IdeS digest of cetuximab $(5 \mu \mathrm{g} / \mu \mathrm{L})$; sample injection $0.5 \mathrm{psi} 50 \mathrm{~s}$.

Figure 3. Impact of ammonium acetate concentration in outlet BGE on electrophoretic resolution. Inlet BGE composed by a mixture of EACA $200 \mathrm{mM}$ and acetate ammonium $25 \mathrm{mM} \mathrm{pH} 5.70$ and outlet BGE by ammonium acetate (A) $12.5 \mathrm{mM}$, (B) $25 \mathrm{mM}$, (C) $50 \mathrm{mM}$ and (D) $100 \mathrm{mM}$, at $\mathrm{pH}$ 5.70. Peak 1-3 correspond to $\mathrm{Fc} / 2$ variants and peak 4-6 correspond to $\mathrm{F}\left(\mathrm{ab}^{\prime}\right) 2$ variants. Experimental conditions: HPCcoated capillary, total/effective length $82 / 75.5 \mathrm{~cm}$ x $75 \mu \mathrm{m}$ i.d.; voltage, $20 \mathrm{kV}$; UV absorbance at $200 \mathrm{~nm}$; sample injection 0.5 psi $50 \mathrm{~s}$.

Figure 4. CZE-UV off-line coupled to MALDI-MS via fractionation for a middle-up characterization of Cetuximab charge variants. (a) CZE-UV electropherogram. (b) Analysis of CZE-UV fractions by MALDI-MS. Mass spectra of the six major peaks. CE Experimental conditions: Inlet BGE: EACA 200 mM acetate ammonium 25 mM pH 5.70 and outlet BGE: ammonium acetate 25 mM pH 5.70; other conditions: See Figure 2, MS Experimental conditions: See Experimental section; sample, IdeS digest of cetuximab ( $5 \mu \mathrm{g} / \mu \mathrm{L})$; sample injection 0.5 psi 50 s.

Figure 5. (a) Off line CZE-UV/ESI-MS separation of middle-up cetuximab charge variants. (b) Deconvoluted mass spectra for each Fc/2 variant. The MS peak were labeled with the correspondent glycoform. Experimental conditions: Inlet BGE: EACA 200 mM ammonium acetate $25 \mathrm{mM} \mathrm{pH} 5.70$ and outlet BGE: ammonium acetate $25 \mathrm{mM} \mathrm{pH}$ 5.70; other conditions: See Figure 2, MS Experimental conditions: See Experimental section; sample, IdeS digest of cetuximab $(5 \mu \mathrm{g} / \mu \mathrm{L})$; sample injection $0.5 \mathrm{psi} 50 \mathrm{~s}$.

Figure 6. (a) Off line CZE-UV/ESI-MS separation of middle-up cetuximab charge variants. (b) Deconvoluted mass spectra for each F(ab') 2 variant. The MS peak were labeled with the correspondent glycoform. Experimental conditions: Inlet BGE: EACA 200 mM ammonium acetate $25 \mathrm{mM} \mathrm{pH} 5.70$ and outlet BGE: ammonium acetate $25 \mathrm{mM} \mathrm{pH} \mathrm{5.70;} \mathrm{other} \mathrm{conditions:} \mathrm{See} \mathrm{Figure} \mathrm{2,} \mathrm{MS} \mathrm{Experimental} \mathrm{conditions:} \mathrm{See}$ Experimental section; sample, IdeS digest of cetuximab $(5 \mu \mathrm{g} / \mu \mathrm{L})$; sample injection $0.5 \mathrm{psi} 50 \mathrm{~s}$. 
Table of content (TOC) graphics

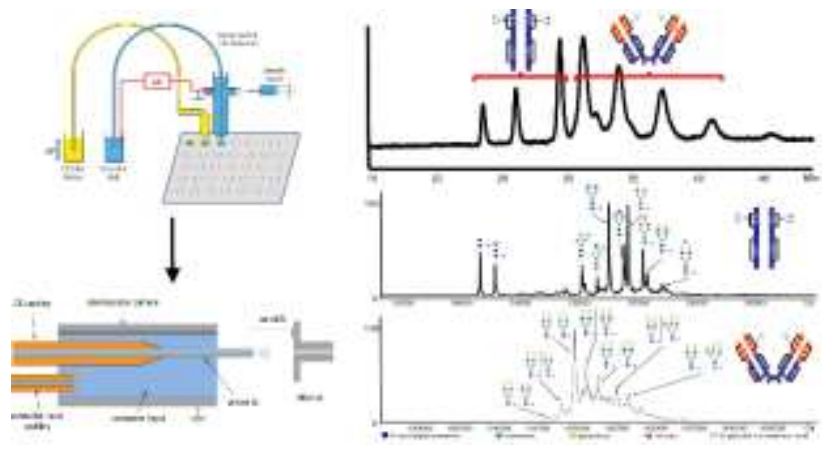

